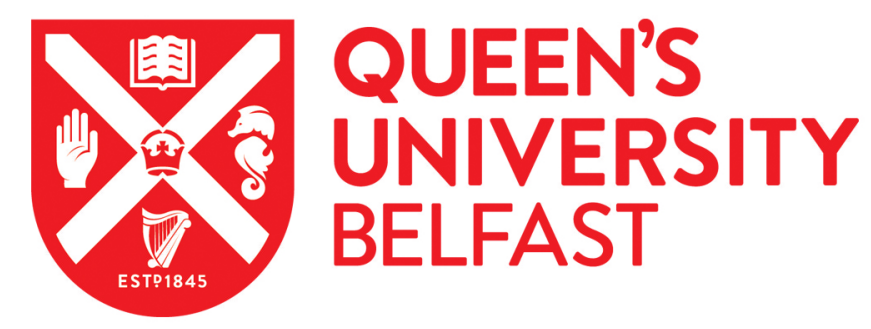

\title{
An energy based force prediction method for UD-CFRP orthogonal machining
}

Li, H., Qin, X., He, G., Price, M. A., Sun, D., \& Jin, Y. (2017). An energy based force prediction method for UDCFRP orthogonal machining. Composite Structures, 159, 34-43.

https://doi.org/10.1016/j.compstruct.2016.09.051

Published in:

Composite Structures

Document Version:

Peer reviewed version

Queen's University Belfast - Research Portal:

Link to publication record in Queen's University Belfast Research Portal

Publisher rights

(C) 2016 Elsevier Ltd. All rights reserved.

This manuscript version is made available under the CC-BY-NC-ND 4.0 license http://creativecommons.org/licenses/by-nc-nd/4.0/,which permits distribution and reproduction for non-commercial purposes, provided the author and source are cited.

\section{General rights}

Copyright for the publications made accessible via the Queen's University Belfast Research Portal is retained by the author(s) and / or other copyright owners and it is a condition of accessing these publications that users recognise and abide by the legal requirements associated with these rights.

Take down policy

The Research Portal is Queen's institutional repository that provides access to Queen's research output. Every effort has been made to ensure that content in the Research Portal does not infringe any person's rights, or applicable UK laws. If you discover content in the Research Portal that you believe breaches copyright or violates any law, please contact openaccess@qub.ac.uk. 


\title{
An energy based force prediction method for UD-CFRP orthogonal machining
}

\begin{abstract}
:
The machining of carbon fiber reinforced polymer (CFRP) composite presents a significant challenge to the industry, and a better understanding of machining mechanism is the essential fundament to enhance the machining quality. In this study, a new energy based analytical method was developed to predict the cutting forces in orthogonal machining of unidirectional CFRP with fiber orientations ranging from $0^{\circ}$ to $75^{\circ}$. The subsurface damage in cutting was also considered. Thus, the total specific energy for cutting has been estimated along with the energy consumed for forming new surfaces, friction, fracture in chip formation and subsurface debonding. Experiments were conducted to verify the validity of the proposed model.
\end{abstract}

Keywords: CFRP, Cutting Energy, Cutting mechanics, Force prediction

\section{Introduction}

Due to the demands of the aerospace industry, the lightweight and mechanical properties of materials are becoming increasingly important in recent years [1]. Carbon fiber reinforced polymer (CFRP), as one of new structural composites, is widely used as structural components for aircrafts because of its excellent fracture toughness, stiffness to weight ratio, and low thermal expansion. Components made from CFRP are mostly produced by the near-net-shape method, however, secondary manufacturing processes, such as trimming, milling, and drilling, are often required for imparting dimensional tolerance and assembly of composite parts [2]. However, owing to the unique anisotropic characteristics of the material, it is still a challenge to machine CFRP with high-precision surface without delamination, fiber pull-out, or burning $[2,3]$. Although orthogonal cutting is uncommon in industrial machining processes, the analytical approach of such machining process is essential for better understanding the mechanisms of common processing methods such as drilling, milling, and trimming, etc.

To date, most published work concerning orthogonal cutting of CFRP are mostly focused on the regularity of chip formation $[4,5]$, revealing the machining mechanism by finite element method (FEM) [6,7] and on the prediction model of cutting forces $[8,9]$. The machinability of CFRP mainly depends on the properties of fibers and matrix and the fiber orientation $[10,11]$. When the fiber orientation $\theta$ is $0^{\circ} \sim 90^{\circ}$, mode II fiber failure occurs under compressive shear; when the $\theta$ is $90^{\circ} \sim 180^{\circ}$ at a positive rake angle, mode I fracture initiates along the fiber-matrix interface and fiber failure occurs when the bending stress exceeding the bending limit of the fiber [2]. On the basis of experimental investigation, FEM has been used to predict cutting force and delamination in CFRP orthogonal cutting process. Nayak et al. [12] proposed a model with two-phase material system consisting of distinct physical entities, i.e. a single fiber and surrounding matrix. By adopting plane stress, Tsai-Hill failure and fiber-matrix separation criteria, the consistency of the two-phase micromechanical 
model was compared to the equivalent homogeneous material (EHM) model. Taking the fiber and matrix failure into consideration, Rao et al. $[13,14]$ used the FEM to predict the damage and chip-formation mechanism for $\theta$ is less than $90^{\circ}$. Calzada et al. [15] introduced a new approach to interfacial modeling where the material interface is modeled using continuum elements, allowing failure to take place in either tension or compression. The model is capable of describing the fiber failure mode occurring throughout the chip formation process.

The above mentioned models successfully predicted the chip formation mechanism, subsurface damage and cutting force but failed to map the relationship between the cutting force and other key variables, such as cutting parameters, cutting tool parameters and material properties. Several studies on CFRP cutting force have adopted the Merchant shear plane theory for developing the constitutive approach [5]. Zhang et al. [16,17] developed a mechanical model to predict cutting force by dividing the cutting zone into three regions: chipping, pressing and bouncing. The model was also based on the shear plane theory and some fundamental material mechanics principles. Since the chip-formation mechanism in composites machining is different from that of metals, the cutting theories of metals cannot be directly applied to composites. Recently, Zhang and co-workers [18] successfully established the cutting force and deformation model for cutting UD-FRP composites $\left(\theta=90^{\circ}\right)$ with and without vibration of tool tip. Their research established essential fundamentals to understand the science behind the orthogonal cutting and the elliptic vibration-assisted (EVA) cutting. However, situations for $\theta$ other than $90^{\circ}$ have not been investigated. To better understand the cutting mechanism of composites, Sahraie Jahromi and Bahr [19] developed a new analytical method for predicting the cutting forces $\left(\theta=90^{\circ} \sim 180^{\circ}\right)$ by applying the principle of virtual work. This model promoted composites analytical research, transforming the composite from an equivalent homogeneous material to a multiphase material. Based on this method, a more precise cutting force model for $\theta$ range from $0^{\circ}$ to $90^{\circ}$ was developed [20]. In this model the supporting effect of surrounding materials was considered, and the deflection differential equation was obtained by the principle of minimum potential energy.

The above literatures indicated that the CFRP material removal mechanism is associated with the micro-failure of fibers, and relevant prediction models for cutting force can be obtained based on such analysis. The objective of this work is to develop a new analytical method, to identify the energy consumption law and the defect formation mechanism in CFRP orthogonal cutting. Relevant experiments are carried out to examine the established model.

\section{Mechanics modeling}

\subsection{Analysis of energy distribution}

The cutting mechanisms of CFRP are different for $0^{\circ}<\theta<90^{\circ}$ and $90^{\circ}<\theta<180^{\circ}$ [2]. This paper will focus on analyzing the mechanism of UD-CFRP cutting based on an energy conservation method for the $0^{\circ}<\theta<90^{\circ}$.

In CFRP orthogonal cutting process with a cutting speed $V_{c}$, the increment of external work, $E_{\text {ext }}$, is given by $F_{c} V_{c}$. Under steady-state conditions, the energy remains 
unchanged and the increment external work equals to the increment of dissipated energy. As shown in Fig. 1, the dissipated energy in CFRP orthogonal cutting process consists of: (i) $E_{\text {surf }}$, energy consumed for formation of new surfaces, (ii) $E_{\text {fric }}$, friction energy at the tool-chip interface, (iii) $E_{c h i p}$, fracture energy for chip formation, (iv) $E_{d e b}$, energy consumption for subsurface damage (debonding in this paper). Therefore, under steady state conditions, there is no change in elastic energy and the law of energy conservation applies:

$$
E_{\text {ext }}=F_{c} V=E_{\text {surf }}+E_{\text {fric }}+E_{\text {chip }}+E_{\text {deb }}
$$

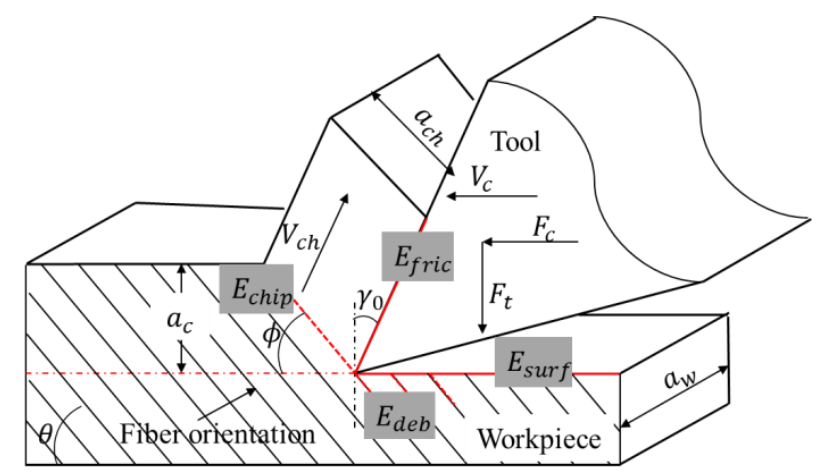

Fig. 1 Energy consumption in orthogonal cutting of UD-CFRP

\subsection{Energy consumed for new surface formation, $\boldsymbol{E}_{\text {surf }}$}

In the pioneering studies of machining [21,22], the calculated results of energy associated with the formation of new surfaces was negligible and subsequent analyses of metal cutting have been mostly on plastic deformation and friction only. This view has been widely accepted until Atkins claimed that the work for new surface formation was a significant component of the total work done in cutting [23]. Therefore the new surface fracture energy is given by

$$
E_{\text {surf }}=G_{c} a_{w} V_{c}
$$

As shown in Fig. 1, it is assumed that the toughness $G_{c}$ represents the total energy per unit projected area dissipated in machined surface. For an orthotropic plate under plane stress, the fracture energy $G_{c}$ is related to the fracture toughness $K_{c}$ by

$$
G_{c}=K_{c}^{2} / E_{c}
$$

Where $E_{c}$ is the modulus of the composite.

For a thin crack in an infinite sheet under tension normal to the crack, the fracture toughness of the composite can be estimated as follows [24]

$$
K_{c}=\sqrt{\frac{2 E_{c}}{\left(1-v_{c}^{2}\right)}\left\{\left(1-v o l_{f}\right) \gamma_{m}+\frac{v_{f} d \sigma_{f}^{3}}{12 \sigma_{s} E_{f r}}\right\}}
$$

where $v_{c}$ is the Poisson's ratio of the composite. $\gamma_{m}$ the fracture surface energy of the matrix, and $E_{f r}$ can be obtained by 


$$
E_{f r}=\frac{\left(1-v_{f}\right) E_{f}}{\left(1+v_{f}\right)\left(1-2 v_{f}\right)}
$$

Where $E_{f}$ and $v_{f}$ are the modulus and Poisson's ratio of the fiber.

\subsection{Friction energy at the tool-chip interface, $E_{\text {fric }}$}

The friction energy consumed at the tool-chip interface is estimated by the friction force $f$ on the rake face and the chip flow velocity $V_{c h}$. Comparing with homogenous and ductile materials, CFRP is elastic-brittle and exhibits very little plastic deformation or if any at all [25]. The plastic deformation during the cutting process can be neglected and we have $V_{c}=V_{c h}$, the friction energy can therefore be given by

$$
E_{\text {fric }}=f \cdot V_{c h}=f \cdot V_{c}
$$

The friction produced by normal concentrated force applied by the cutting edge is given by $f=\mu \cdot N$. Based on the previous experimental study [26], the friction coefficient increases with increasing $\theta$ and the variation is range of from 0.2 to 0.35 . In this study, a friction coefficient of 0.3 was selected.

The loading condition which contributes to the friction force is shown in Fig. 2. In the CFRP orthogonal cutting process, the chip formation mechanism was basically determined by the fiber orientation [2]. As shown in Fig. 2(b), when $\theta \geq \gamma_{0}$, the chips are formed by the matrix shear fracture along the fiber orientation. The force associated with the matrix shear failure could be estimated by

$$
F_{s}=a_{w} a_{c} S_{m} / \sin \theta
$$

Under this situation, chips are produced by shearing the matrix-fiber interface along the fiber direction. Therefore, the shear plane angle can be replaced by fiber angle. Based on the cutting force balance relationship, the force normal to the tool-chip interface can be expressed as follows

$$
N_{1}=\frac{F_{s} \cos \beta}{\cos \left(\theta+\beta-\gamma_{0}\right)}
$$

where $\beta=\arctan \mu$.

As shown in Fig. 2(a), when $\theta<\gamma_{0}$, the chips are pelt off due to the force produced by the rake face. The force could be expressed as follows [27]

$$
N_{2}=K_{p} \sqrt{\frac{2\left(1-v_{E H M}\right) G_{m}}{E_{E H M}}} \frac{a_{c} \pi}{\cos \theta} S_{m} \cot \gamma_{0} \cos \beta
$$

Combining Eq. (8) and (9), the force in the direction normal to tool-chip interface can be expressed by

$$
N=\left\{\begin{array}{lr}
N_{2}=K_{p} \sqrt{\frac{2\left(1-v_{E H M}\right) G_{m}}{E_{E H M}}} \frac{a_{c} \pi}{\cos \theta} S_{m} \cot \gamma_{0} \cos \beta, \theta<\gamma_{0} \\
N_{1}=\frac{F_{s} \cos \beta}{\cos \left(\theta+\beta-\gamma_{0}\right)}, & \theta \geq \gamma_{0}
\end{array}\right.
$$


The force $N$ is continuous with $\theta$ and the boundary point of the functions is $\theta=\gamma_{0}$, based on the mathematical properties of continuous functions, we have $N_{1}\left(\theta=\gamma_{0}\right)=N_{2}\left(\theta=\gamma_{0}\right)$ and the following equation can be obtained

$$
N_{2}=a_{c} a_{w} S_{m} \frac{\cot \gamma_{0} \cos \beta}{\cos \left(\theta+\beta-\gamma_{0}\right) \cos \theta}
$$

Combining Eq. (8) and (11), the friction force on the rake face can be expressed as

$$
f=N \cdot \mu= \begin{cases}a_{c} a_{w} S_{m} \frac{\cot \gamma_{0} \sin \beta}{\cos \theta \cos \left(\theta+\beta-\gamma_{0}\right)} & \theta<\gamma_{0} \\ \frac{a_{w} a_{c} S_{m} \sin \beta}{\sin \theta \cos \left(\theta+\beta-\gamma_{0}\right)} & \theta \geq \gamma_{0}\end{cases}
$$

and the friction energy on the tool-chip interface can be obtained through Eq. (6) and (12).

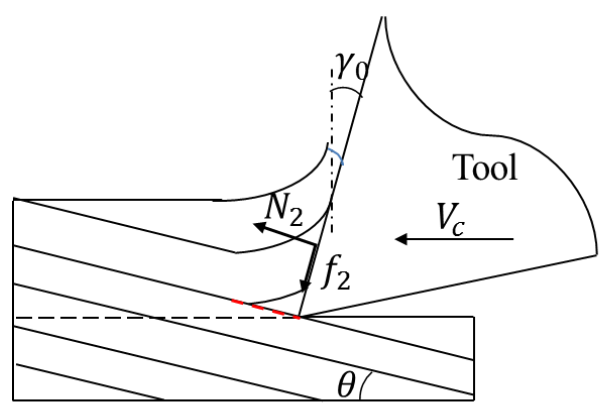

(a) $\theta<\gamma_{0}$

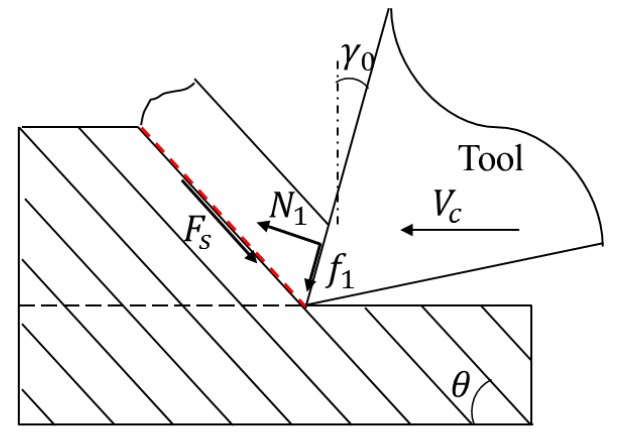

(b) $\theta \geq \gamma_{0}$

Fig. 2 Loading condition of rake face under different fiber orientation[20]

\subsection{Fracture energy during the chip formation, $E_{\text {chip }}$}

According to the chip formation mechanism, when $\theta$ is lower than $\gamma_{0}$, as shown in Fig. 3(a), Mode I fracture initiates along the fiber-matrix interface causing a layer to peel and slide along the rake face [2]. With an increasing cutting tool feed, the chip becomes a cantilever beam under a bending loading. Therefore, there are two fracture processes taking place simultaneously, Mode I fracture along the fiber-matrix interface $\left(G_{\mathrm{IC}}\right)$ and bending fracture $\left(G_{c}\right)$ when the bending stress exceeds the bending limit of fibers, before the chip formation, as indicated by the red dash line in Fig. 3(a). Thus, the total energy consumption for single chip formation can be estimated by

$$
E_{c h i p}^{\prime}=a_{c} a_{w} G_{c}+\frac{d}{\cos \theta} a_{w} G_{\mathrm{IC}}
$$

where $d$ is the chip block thickness which can be measured directly from experiment, as illustrated in Fig. 3(a), and the frequency of chip formation can be expressed as $V_{c} / d$. Thus, the chip fracture energy $\left(\theta<\gamma_{0}\right)$ can be expressed by

$$
E_{\text {chip }}=E_{\text {chip }}^{\prime} \frac{V_{c}}{d}=\left(a_{c} G_{c}+\frac{d}{\cos \theta} G_{\mathrm{IC}}\right) \frac{a_{w} V_{c}}{d}
$$


When $\gamma_{o} \leq \theta<75^{\circ}$, as shown in Fig. 3(b), the chip formation process is predominated by Mode II fracture under a compressive shear along the fiber direction [2], as indicated by the thick red dashed line in Fig. 3(b). Thus, the energy consumption for single chip formation when $\theta \geq \gamma_{0}$ can be estimated by

$$
E_{\text {chip }}^{\prime}=\frac{a_{c} a_{w}}{\sin \theta} G_{\mathrm{IIC}}
$$

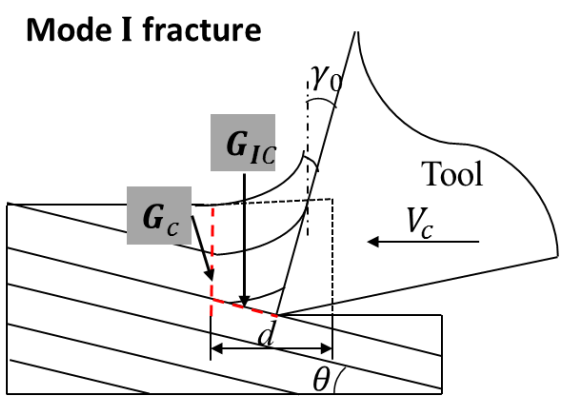

(a) $\theta<\gamma_{0}$

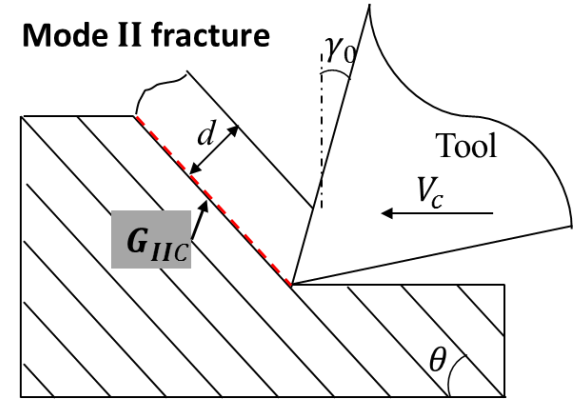

(b) $\theta \geq \gamma_{0}$

Fig. 3 Analysis for chip formation energy under different fiber orientation

Based on the chip thickness $d$, see Fig. 3(b), the frequency of chip formation can be expressed as $V \cdot \sin \theta / d$ and chip fracture energy for $\theta \geq \gamma_{0}$ can be obtained

$$
E_{\text {chip }}=E_{\text {chip }}^{\prime} \frac{V_{c} \sin \theta}{d}=G_{\mathrm{II}} \frac{a_{c} a_{w} V_{c}}{d}
$$

Combining Eqs. (14) and (16), the fracture energy during the chip formation can be expressed as

$$
E_{c h i p}=\left\{\begin{array}{cc}
\left(a_{c} G_{c}+\frac{d}{\cos \theta} G_{\mathrm{IC}}\right) \frac{a_{w} V_{c}}{d} & \theta<\gamma_{0} \\
G_{\mathrm{IIC}} \frac{a_{c} a_{w} V_{c}}{d} & \theta \geq \gamma_{0}
\end{array}\right.
$$

where $G_{\text {IC }}$ is the mode I and $G_{\text {IIC }}$ is the II fracture toughness of CFRP along the fiber-matrix interface, both of which can be obtained through the fracture toughness tests.

\subsection{Prediction of energy consumption for subsurface damage, $\boldsymbol{E}_{d e b}$}

The cutting process shown in Fig.1 is an ideal state of energy distribution, while in the real cutting process, the machining defects also need to be taken into consideration. The extent of damage below the machined surface is considered as sub-surface damage. It can be due to the damage of matrix or interfacial debonding or a combination of both $[13,14]$. Fig. 4 (a) shows a schematic view of fiber and matrix deformation before fiber failure and creating new surface and the debonding below the machined surface was produced owing to the bending of fiber (red line shown in Fig. 4(a)). The loading condition on one representative volume element is shown in Fig. 4(b). Before the analysis, the following assumptions are made based on earlier studies $[19,28]$, 


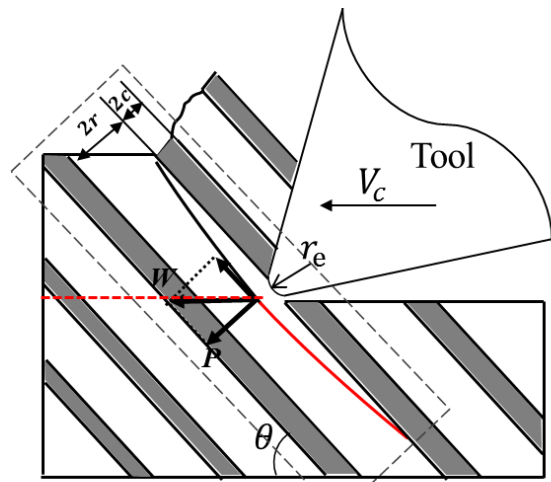

(a)

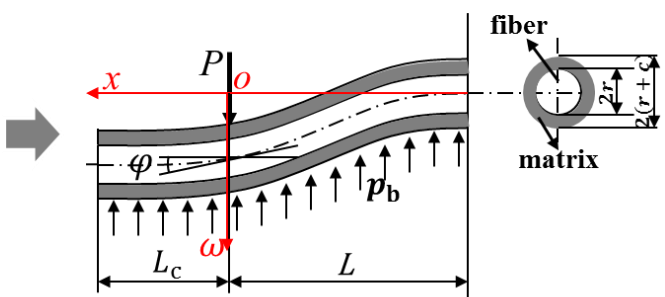

(b)

Fig. 4 Schematic of (a) formation of sub-surface damage and (b) loading condition in region highlighted by dashed line.

1. Analysis is based on plane deformation.

2. Shear stress in fiber is negligible.

3. No matrix extension or compression occurs.

4. Normal stress in the fiber produces no mechanical work during deformation of fiber.

Referring to Fig. 4, a representative volume of composite consists of a fiber and the surrounding matrix will bend under the concentrated force $P$ (applied by the cutting edge) and passive pressure $p_{b}$, the deflection equation can be obtained by the energy method. The boundary conditions in this case can be written as

$$
\left\{\begin{array}{l}
x=0:\left.\frac{d \omega}{d x}\right|_{x=0}=0 \\
x=-\infty: \omega(-\infty)=0,\left.\frac{d \omega}{d x}\right|_{x=-\infty}=0
\end{array}\right.
$$

The plane shear strain in the matrix materials can be obtained by the following equation [28]

$$
\gamma_{m}=\left(\frac{c+r}{c}\right) \frac{d \omega}{d x}
$$

and the shear stress can be expressed as

$$
\tau_{m}=G_{m} \gamma_{m}=G_{m}\left(\frac{c+r}{c}\right) \frac{d \omega}{d x}
$$

Therefore, the strain energy of the matrix can be expressed by

$$
U_{m}=\frac{1}{2} A_{m} \int_{-\infty}^{L_{c}} \tau_{m} \gamma_{m} d x=\frac{1}{2} A_{m} G_{m}\left(\frac{c+r}{c}\right)^{2} \int_{-\infty}^{L_{c}}\left(\frac{d \omega}{d x}\right)^{2} d x
$$

where

$$
A_{m}=\frac{\pi r^{2}\left(1-v o l_{f}\right)}{v o l_{f}}, \quad c=r\left(\frac{1}{2} \sqrt{\frac{\pi}{v o l_{f}}}-1\right)
$$

The strain energy in the fiber due to bending can be expressed as

$$
U_{f}=\frac{1}{2} \int_{-\infty}^{L_{c}} E_{f} I_{f}\left(\frac{d^{2} \omega}{d x^{2}}\right)^{2} d x
$$


The work of passive pressure $p_{b}$ could be obtained based on Winkler foundation model [28] and Zhang's evolution [20]

$$
W_{p_{b}}=\int_{-\infty}^{L_{c}} \omega d p_{b}=-\frac{E_{b}}{k} \int_{-\infty}^{L_{c}} \omega^{2} d x
$$

where $E_{b}$ is the equivalent Young's modulus associating with $E_{f}$ and $E_{m}$,

$$
E_{b}=\frac{E_{f} E_{m}}{E_{f}+E_{m}}
$$

The work of the concentrated force $P$ can be expressed as

$$
W_{P}=P \cdot \omega(0)
$$

Combining Eqs. (21), (23), (24) and (26), the total potential energy in the process of fiber deformation can be obtained

$$
\begin{aligned}
& U=U_{f}+U_{m}-W_{P}-W_{p_{b}} \\
& =\frac{1}{2} \int_{-\infty}^{L_{c}} E_{f} I_{f}\left(\frac{d^{2} \omega}{d x^{2}}\right)^{2} d x+\frac{1}{2} A_{m} G_{m}\left(\frac{c+r}{c}\right)^{2} \int_{-\infty}^{L_{c}}\left(\frac{d \omega}{d x}\right)^{2} d x+\frac{E_{b}}{k} \int_{-\infty}^{L_{c}} \omega^{2} d x-P \cdot \omega(0)
\end{aligned}
$$

Based on the principle of minimum potential energy, the first order variation of the total potential energy equals to zero

$$
\delta U=0
$$

Thus, the following equation can be obtained

$$
E_{f} I_{f}\left(\omega^{(4)}\right)-A_{m} G_{m}\left(\frac{r+c}{c}\right)^{2} \omega^{\prime \prime}+\frac{2 E_{b}}{k} \omega=0
$$

Eq. (29) is a differential equation with four orders, thus, four boundary conditions are required to solve this equation. One of the bounding conditions can be obtained through the fiber failure fracture. As shown in Fig. 4(a), the fiber is subjected to a horizontal force $W$ when the cutting edge is in contact with workpiece, this causes the material to yield and creates a new machined surface (red dash line in figure).

This process can be viewed as the contact between a circular cylinder (tool nose) and a plane (workpiece material), as shown in Fig. 5. The distribution of the normal pressure in the contact zone can be described by the following equation [29]:

$$
p=p_{H}\left(1-\frac{y^{2}}{b^{2}}\right)^{1 / 2}
$$

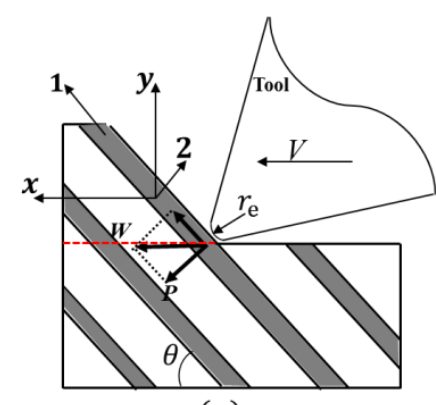

(a)

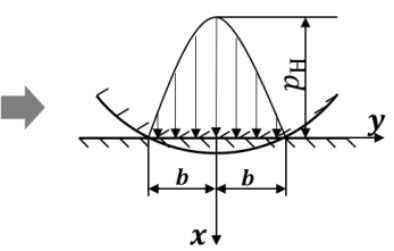

(b)

Fig. 5 (a) Conversion between two coordinate systems and (b) stress distribution in the contact zone. 
where $p_{H}=2 W / \pi b a_{w}$ and half-width of the contact zone $b=\left(4 W r_{e} / \pi L E^{*}\right)^{1 / 2}$, and $E^{*}$ is the equivalent elastic modulus in the contact zone. The equivalent elastic modulus can be obtained through the following equation

$$
\frac{1}{E^{*}}=\frac{1-v_{\text {tool }}^{2}}{E_{\text {tool }}}+\frac{1-v_{y x}^{2}}{E_{x}}
$$

$v_{y x}^{2}$ is a parameter dependent on $\theta$, which ranges from 0.1 to 0.3 , here we use the mean value 0.2 for simplify. $E_{x}$ is dependent on $\theta$ and can be expressed through the conversion between two coordinate systems (as shown in Fig. 5)

$$
\frac{1}{E_{x}}=\frac{1}{E_{1}} \cos ^{4} \theta+\left(\frac{1}{G_{12}}-\frac{2 v_{21}}{E_{1}}\right) \sin ^{2} \theta \cos ^{2} \theta+\frac{1}{E_{2}} \cos ^{4} \theta
$$

The fiber fractures when the tensile stress in the fiber reaches its tensile strength [18]. The tensile stress in the fiber can be described by [30]:

$$
\sigma_{T}=\frac{1}{2}\left(\sigma_{x}+\sigma_{y}\right)+\frac{1}{2}\left[\left(\sigma_{x}+\sigma_{y}\right)^{2}+4 \tau_{x y}^{2}\right]^{1 / 2}
$$

Details for calculating the Cartesian components of stress field $\left(\sigma_{x}, \sigma_{y}, \tau_{x y}\right)$ can be found in [31].

The concentrated force $W$ can be expressed as resultant force of friction force along the fiber and bending force $P$. Thus, the bending force can be obtained as

$$
P=W \cos \theta
$$

Thus, the deflection of the representative volume element (Fig. 4(b)) in $x=0$ when the fiber fracture initiates can be estimated as

$$
\left.\omega\right|_{x=0}=\frac{P}{k_{m}}
$$

Where $k_{m}$ is the modulus of the foundation equivalent homogeneous material (EHM), which can be obtained by [32]

$$
k_{m}=\frac{0.95 E_{e h m}}{\left(1-v_{e h m}^{2}\right)}\left[\frac{D}{E_{f} I_{f}\left(1-v_{e h m}^{2}\right)}\right]^{0.108}
$$

Combing Eq. (18) and (35), the differential equation (Eq. (29)) can be solved. In this work, the software Matlab was used. From the result of the deflection function $\omega(x)$, the debonding point $x_{d}$ below the machined surface can be determined as

$$
\omega\left(x_{d}\right)=c \frac{\sigma_{b}}{E_{m}}, \quad x_{d}<0
$$

where $\sigma_{b}$ is the bonding strength of matrix and fiber interface. From Eq. (37), the subsurface debonding length can be estimated to be $\left|x_{d}\right|-r_{e}$. The formation frequency of debonding is $V_{c} \sin \theta / 2 c$. Therefore, the energy consumption for subsurface damage can be expressed as

$$
E_{d e b}=G_{\mathrm{I}}^{\prime} a_{w}\left(\left|x_{d}\right|-r_{e}\right) \frac{V_{c} \cdot \sin \theta}{2 c}
$$


The models above are concerned with four types of energy consumed during CFRP orthogonal cutting process and the horizontal cutting force can therefore be expressed

$$
F_{c}=\frac{E_{\text {surf }}+E_{\text {fric }}+E_{\text {chip }}+E_{\text {deb }}}{V_{c}}
$$

\section{Experimental}

Experiments were conducted to measure the cutting force. Fig. 6 shows the schematic of the experiment setup. Orthogonal cutting tests were carried out using specially designed cutting tools on a JOHNFORD (VMC-850) vertical machining center. The tool matrix material is tungsten carbide and in order to ensure the sharpness of cutting edges, the tool is uncoated. The rake angle and clearance angle are $15^{\circ}$ and $20^{\circ}$, respectively and the rounded edge radius is $5 \mu \mathrm{m}$. The tool spindle was locked to ensure no rotational motion during the tests. Each test with a special parameter combination was repeated twice. The cutting speed $\left(V_{c}\right)$ was kept $0.5 \mathrm{~m} / \mathrm{min}$ and depth of cut $\left(a_{c}\right)$ were $0.1 \mathrm{~mm}$ and $0.2 \mathrm{~mm}$. A Kistler three-direction stationary dynamometer (9257) with supporting Kistler charge amplifier (type 5070) was used, and data acquisition board and Kistler software were deployed for the horizontal and vertical directions cutting force measurements.

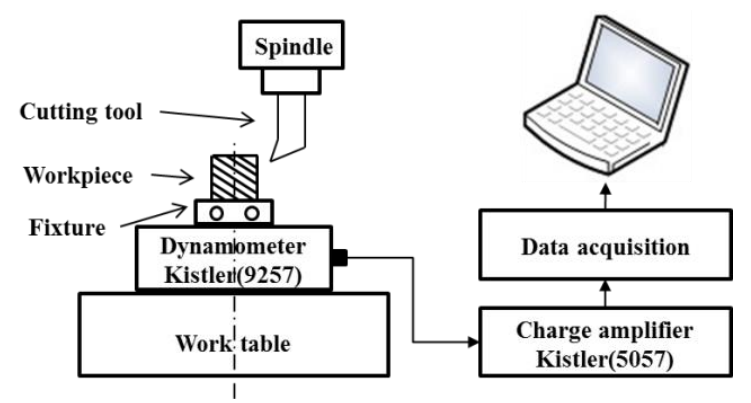

Fig.6 Schematic of the experimental setup

Workpiece materials used in this work were T700/5250BMI unidirectional laminates, which were isotropically layered. The stacking sequences is designed as $\left[0^{\circ}\right]_{48}$, the thickness per layer is $0.125 \mathrm{~mm}$, the final total thickness of the final workpiece is $5 \mathrm{~mm}$. Other material properties are given in Table 1 . In the orthogonal cutting tests, CFRP laminates were cut into small sheet $(90 \mathrm{~mm} \times 50 \mathrm{~mm})$. The orthogonal cutting at different fiber orientations can be achieved by cutting the $0^{\circ}$ CFRP laminates from different directions. When the tool feeding direction rotates and coincides with fiber orientation, the angle of rotation will be defined as the fiber orientation angle, $\theta$. In this paper, the selected fiber angles were: $0^{\circ}, 15^{\circ}, 30^{\circ}, 45^{\circ}, 60^{\circ}, 75^{\circ}$ and $90^{\circ}$. During the cutting process, the produced chips for different fiber angles were also collected to obtain their size by scanning electron microscope (SEM).

Table 1 Material properties of CFRP workpiece

\begin{tabular}{llll}
\hline Fiber radius $(r)$ & $3.5 \mu \mathrm{m}$ & Fiber volume fraction $\left(\right.$ vol $\left._{f}\right)$ & 0.6 \\
Shear modulus of matrix $\left(G_{m}\right)$ & $1.02 \mathrm{GPa}$ & Young's modulus of fiber $\left(E_{f}\right)$ & $230 \mathrm{GPa}$ \\
Shear strength of fiber $\left(\sigma_{s}\right)$ & $0.38 \mathrm{GPa}$ & Bonding strength of interface $\left(\sigma_{b}\right)$ & $30 \mathrm{MPa}$ \\
\hline
\end{tabular}




\begin{tabular}{llll}
\hline Transverse Young's modulus $\left(E_{\text {ehm }}\right)$ & $5.6 \mathrm{GPa}$ & Poisson's ratio $\left(\mathrm{v}_{12}\right)$ & 0.3 \\
Young's modulus of matrix $\left(E_{m}\right)$ & $2.7 \mathrm{GPa}$ & Young's modulus of tool $\left(E_{t}\right)$ & $700 \mathrm{GPa}$ \\
\hline
\end{tabular}

\section{Results and discussion}

\subsection{Chip thickness analysis in CFRP orthogonal cutting}
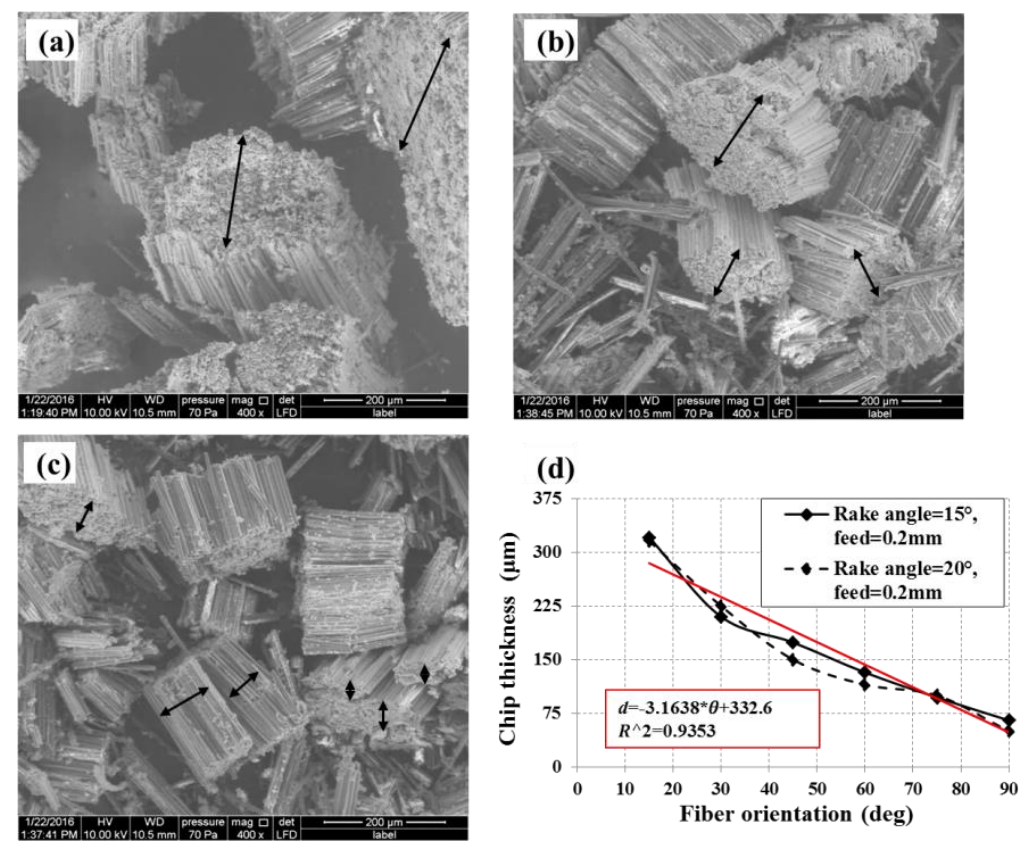

Fig.7 SEM observation results of chip thickness with different fiber orientation: (a) $\theta=30^{\circ}$, (b) $\theta=60^{\circ}$, (c) $\theta=90^{\circ}$ and (d) linear fitting curve based on experimental results.

The chip thickness is a required parameter for calculating the chip formation energy in Eq. (17). Fig. 7(a, b, c) presents the observation results of cutting chips with $\theta=30^{\circ}$, $\theta=60^{\circ}$ and $\theta=90^{\circ}$. The chip thickness (as marked with double-headed arrow) can be measured by SEM and 20 different chips' measured values for each fiber orientation were obtained and the corresponding mean value was shown in Fig. 7(d). It can be found that the chip thickness decreases with the $\theta$ and the influence of $\gamma_{0}$ on chip thickness is relatively small. A linear fitting on the experimental data gives $d=$ $-3.1638 * \theta+332.6$. This expression will be used to estimate the value of chip thickness under different $\theta$ in Eq. (17).

\subsection{Deformation and debonding depth of fiber}

Fig. 8 shows the fiber deformation before fiber fracture occurs during the orthogonal cutting with cutting depth $a_{c}=0.1 \mathrm{~mm}$ and cutting speed $V_{c}=0.5 \mathrm{~m} / \mathrm{min}$. The fiber bending due to the contact pressure of cutting tool nose is presented. The blue line is the deflection of fiber when tensile stress in the fiber reaches the tensile strength, leading to the largest deformation of fiber and matrix. Under such condition, the debonding depth can be obtained through interface bonding strength $\left(\sigma_{b}\right)$. As shown in Fig. 8, the horizontal red line is the limiting deflection value of fiber, when the deflection exceeds this value, the stress at the interface will be larger than the bonding strength and subsurface debonding damage will occur. Combining the coordinate values of $\left(x_{d}\right)$ and cutting tool nose radius $\left(r_{e}\right)$, the debonding length can be obtained. 
When the $\theta$ is $60^{\circ}$, the maximum deflection of fiber is $1.48 \mu \mathrm{m}$ and the debonding length is $7.76 \mu \mathrm{m}$. The variation of debonding damage against $\theta$ is shown in Fig. 9. The subsurface damage increases as $\theta$ changes from $15^{\circ}$ to 90 . The effect of $\gamma_{0}$ on subsurface damage due to matrix degradation is not significant; although, the damage decreases with increasing $\gamma_{0}$ for all depths of cut [13]. The curve shown in Fig. 9 is quadratic fitting curve for six calculated values, the expression of which was also obtained for cutting force and subsurface damage energy prediction in the following section.

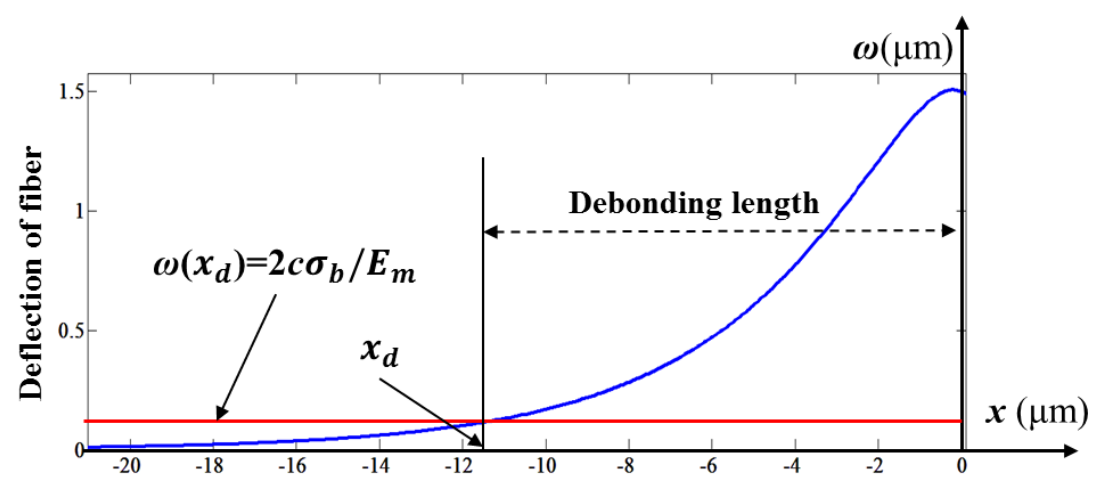

Fig. 8 Deflection of fiber and subsurface debonding length in orthogonal cutting of $\operatorname{UD-CFRP}\left(r_{e}=5 \mu m, \theta=60^{\circ}\right)$

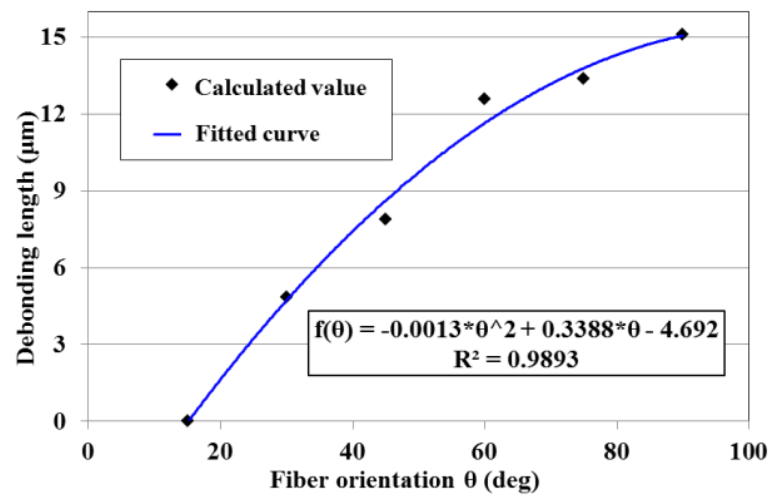

Fig. 9 Variation of subsurface debonding length as a function of fiber orientation

Fig. 10 illustrates the machined CFRP surfaces with different $\theta$. It can be seen that the $\theta$ have great influence on the machined surface integrity. The subsurface debonding length is much smaller for a lower $\theta$, leading to a much smoother surface with negligible surface damage $\left(\theta=0^{\circ}\right.$ or $\left.30^{\circ}\right)$, see Fig. 10(a, b). However, obvious surface damage can be observed when the $\theta$ is $60^{\circ}$ and $75^{\circ}$, see arrows in Fig. 10(c, d). As discussed in Section 2.4 on the mechanics of fiber deformation, the deflection of fiber increases with increasing $\theta$. This can lead to larger fiber-matrix debonding depth and surface defects as shown in Fig. 10(d). The experimental results are in good agreement with the analysis model presented earlier. 

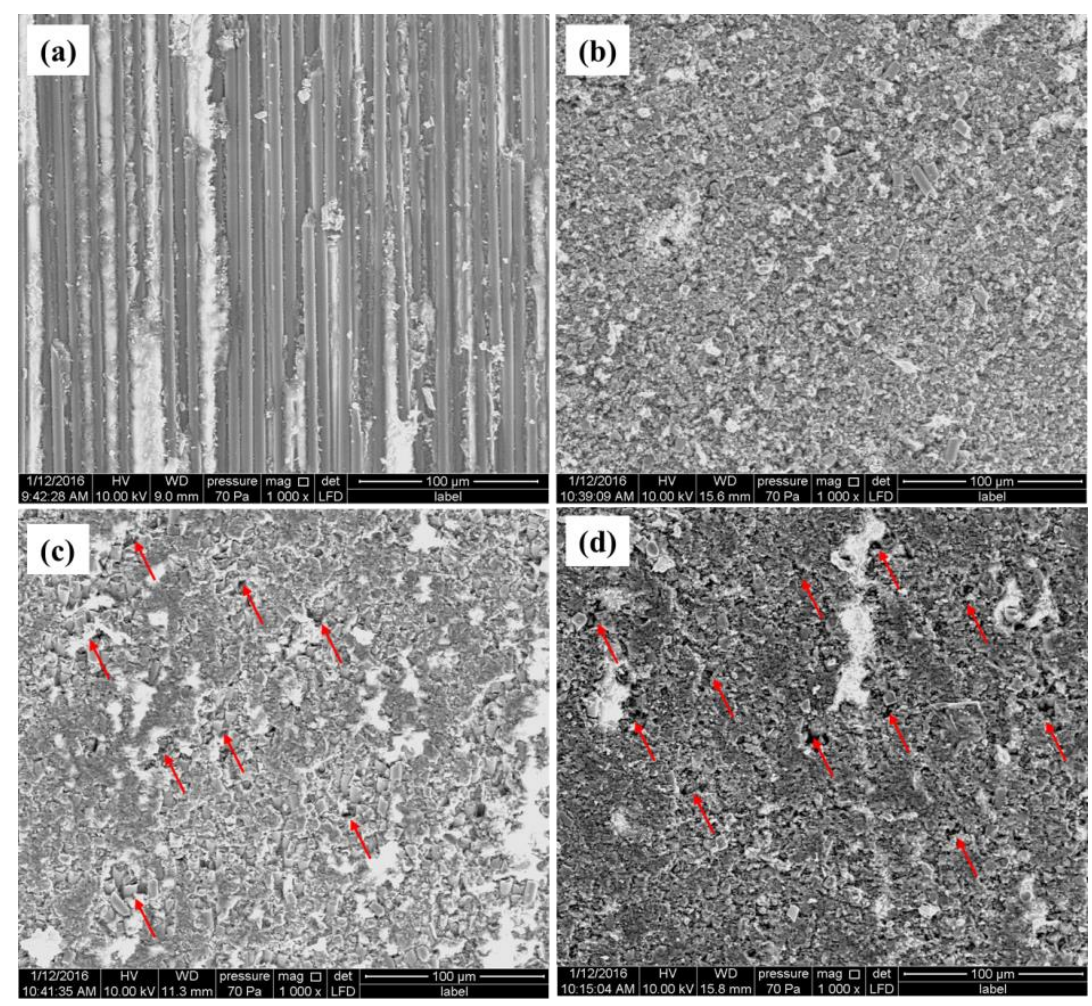

Fig. 10 Machined CFRP surfaces with fiber orientation (a) $0^{\circ}$, (b) $30^{\circ}$, (c) $60^{\circ}$, (d) $75^{\circ}$.

\subsection{Cutting force prediction and cutting energy distribution analysis}

Fig. 11 shows the comparisons of predicted and experimental cutting force using the analytical method for $\gamma_{0}=15^{\circ}$ and $20^{\circ}$. As can be seen, $\theta$ has a significant effect on the force. The cutting force increases with increasing of $\theta$. As indicated by the red arrow in Fig. 12, there is a discontinuity point in the predicted cutting force, which is due to the change in the chip formation mechanism [19]. When the $\theta$ is smaller than $\gamma_{0}$, a Mode I fracture initiates along the fiber-matrix interface causing a layer to peel off; however, when the $\theta$ exceeds the $\gamma_{0}$, the chip formation process is predominated by Mode II fracture.

It can be seen that there is a difference between the predicted and experimental results. The reasons can be summarized as follows. (i) Deviation of material properties used in developed model. The prediction of cutting force from the proposed theory is based on the macro-mechanical properties of fiber and matrix; however, in small deformation zone, the strength of fiber will be higher since the probability and number of defects in the smaller area will be less [31]. (ii) The value of $G_{c}$ in the developed model is estimated through Eq. $(3,4)$. The difference between theoretical and practical values of $G_{c}$ is an important parameter affecting the accuracy of the proposed model. (iii) The irregular fiber distribution in the workpiece material from producing process, can also cause varying fiber volume fractions and lead to variation in cutting force. For the cutting force prediction model in the CFRP orthogonal cutting, the most published literatures were focused on the equilibrium of cutting force, and three characteristic regions, i.e., chipping region, pressing region, and bouncing region, were analyzed respectively. The cutting force was obtained by 
resultant force of these three regions [19, 20,33]. The energy model presented in this paper is based on the fracture toughness and chip thickness, the precision of the model is similar comparing with the force equilibrium method.
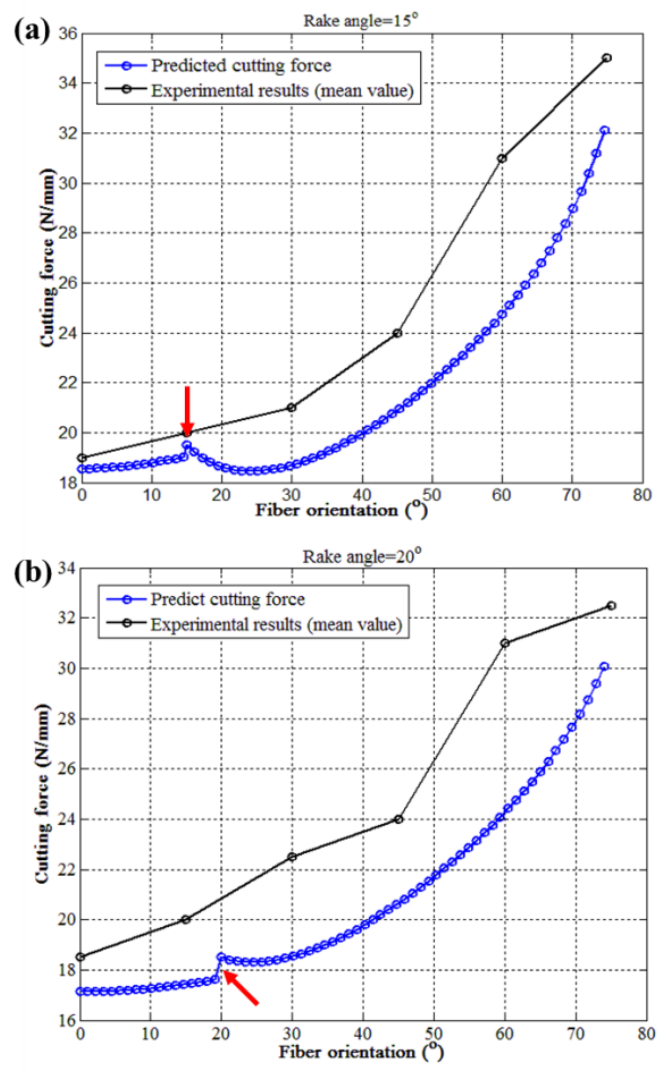

Fig. 11 Predicted and experimental cutting forces vs. fiber orientation, (a) rake angle is $15^{\circ}$ and (b) $20^{\circ}$.

The influence of cutting parameters and fiber orientation on specific cutting energy in CFRP orthogonal cutting was studied. The specific energy will decrease with increasing of cutting speed and depth of cut [34]. However, the influence of $\gamma_{0}$ and $\theta$ on the cutting energy distribution in CFRP orthogonal cutting process has not been reported in the literature. Based on the proposed model in this study, the proportion of energies associated with new surfaces formation $\left(E_{\text {surf }}\right)$, chip formation $\left(E_{\text {chip }}\right)$, friction ( $\left.E_{\text {fric }}\right)$, and subsurface debonding $\left(E_{d e b}\right)$ in cutting process were presented in Fig.12. It is clear that the proportion of each energy varies with fiber orientation, i.e., $E_{\text {surf }}$ and $E_{\text {fric }}$ decrease with increasing $\theta$, while $E_{c h i p}$ and $E_{d e b}$ show an opposite trend. In CFRP cutting, the surface formation energy appears to be the predominant component in the cutting process, which is consistent with the results claimed by Atkin [23] for metal cutting process. As shown in Fig. 12(a), the percentage of energy for new surface energy formation ranges from $49.2 \%$ to $23.2 \%$ when $\gamma_{0}$ is $15^{\circ}$. On average, the energy consumed for tool-chip friction is the greatest, followed by new surface formation, subsurface debonding and chip fracture. 
It is clear that the proportion of each kind of energy varies with fiber orientation, i.e., Esurf and Efric decrease with increasing $\theta$, while Echip and Edeb show an opposite trend. Owing to the sub-surface debonding length increases with $\theta$, which this leads to $E_{\text {deb }}$ increase as well. In the CFRP orthogonal cutting process, chip formation mechanism is dependent on the fiber orientation [35]. When $\theta$ is lower than $\gamma_{0}$, Mode I fracture initiates along the fiber-matrix interface causing the formation of a chip; and when $\gamma_{0} \leq \theta<75^{\circ}$, the chip formation process is predominated by Mode fracture along the fiber direction [2]. The value of fracture toughness of Mode I is smaller than the Mode II, this would cause proportions of $E_{\text {chip }}$ increase with increasing of $\theta$. The cutting tool rake angle is another important factor influence the energy proportion when $\theta$ is lower than $\gamma_{0}$. Larger $\gamma_{0}$ leads to lower $E_{\text {fric }}$ but higher $E_{c h i p}, E_{\text {surf }}$ and $E_{d e b}$. This might be caused by the decreasing normal force on the rake face of cutting tool with larger $\gamma_{0}$. When $\theta$ is larger than $\gamma_{0}$, the rake angle almost has no influence on the results.
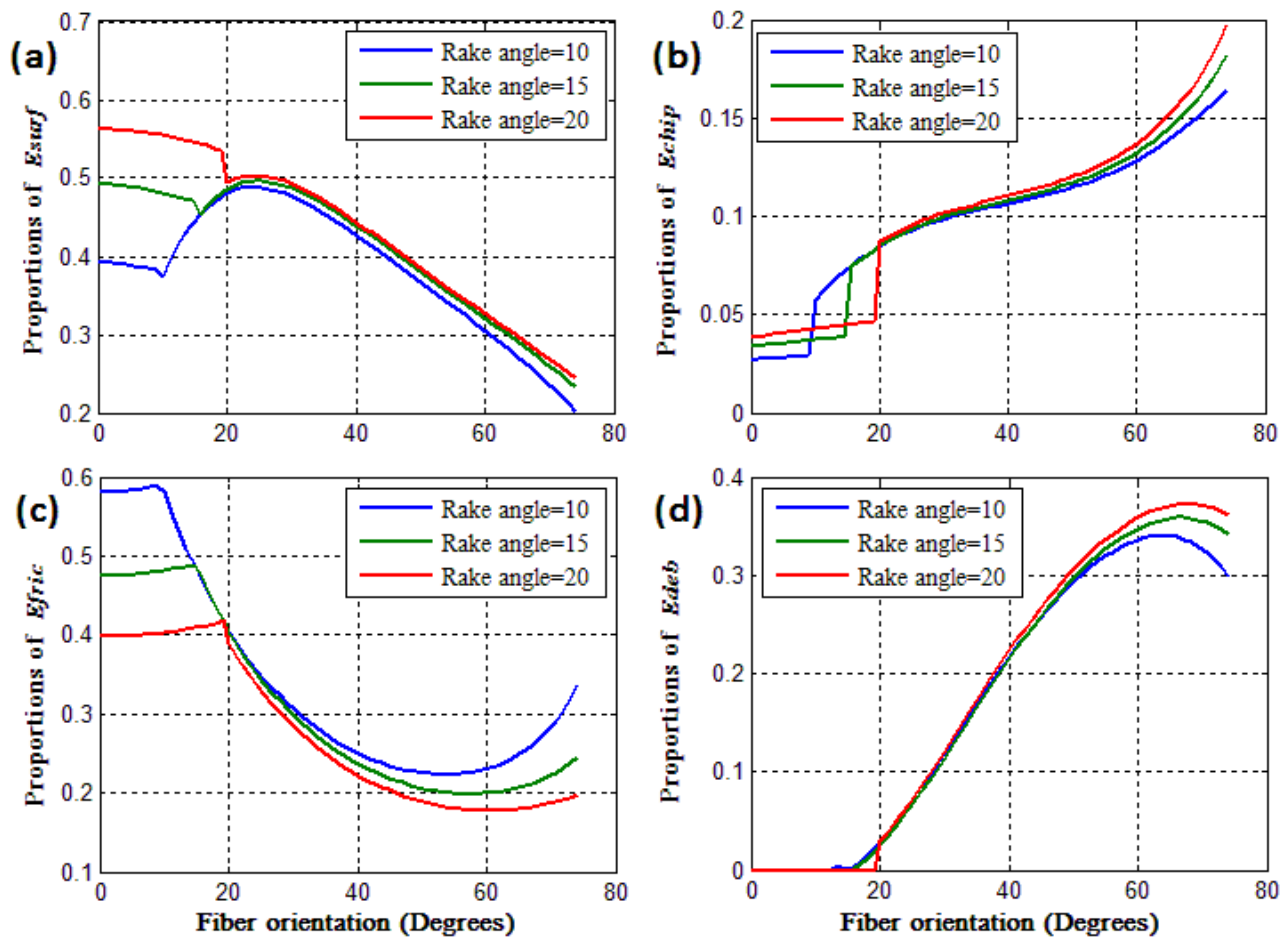

Fig. 12 Proportions of total energy due to (a) creating new surfaces, (b) chip formation, (c) friction and (d) subsurface debonding.

\section{Conclusion}

This paper has established the mechanic model of cutting unidirectional CFRP composite deploying an energy method. Four energy consumption pathways have been proposed, which are energies for new surface formation, friction, chip fracture and subsurface debonding. The validity of the model has been verified by experiments. The proposed model indicates that, fiber orientation has a significant impact on the cutting forces in unidirectional composites. 
From the modeling results, the energy consumed on tool-chip friction is the greatest, followed by the energy for new surface formation, subsurface debonding and chip fracture. The percentage of each energy varies with fiber orientation, with the energy for new surface formation and friction decrease with increasing fiber orientation angle, whereas energy for chip formation and subsurface debonding increase with increasing fiber orientation.

The proposed model is in agreement with experimental data. This demonstrates that the energy consumption method is an effective way in predicting cutting force and facilitates mechanical analysis in CFRP cutting process.

\section{Acknowledgements}

The authors would like to acknowledge the financial support by National Natural Science Foundation of China (Nos. 51275345 \& 51420105007) and Natural Science Foundation of Tianjin (No. 16JCZDJC38300).

\section{References:}

[1] Bonnet C, Poulachon G, Rech J, Girard Y, Costes JP.Cfrp drilling: fundamental study of local feed force and consequences on hole exit damage. International Journal of Machine Tools \& Manufacture.2015;94:57-64.

[2] Soussia AB, Mkaddem A, Mansori ME.Rigorous treatment of dry cutting of FRP - Interface consumption concept: A review. International Journal of Mechanical Sciences.2014;83:1-29.

[3] Che D, Saxena I, Han P, Guo P, Ehmann KF.Machining of Carbon Fiber Reinforced Plastics/Polymers: A Literature Review. Journal of Manufacturing Science \& Engineering.2014;136:1588-94.

[4] Nayak D, Bhatnagar N, Mahajan P.MACHINING STUDIES OF UNI-DIRECTIONAL GLASS FIBER REINFORCED PLASTIC (UD-GFRP) COMPOSITES PART 1: EFFECT OF GEOMETRICAL AND PROCESS PARAMETERS. Machining Science \& Technology.2005;9:481-501.

[5] X NB.On the machining of fiber reinforced plastic (FRP) composite laminates. International Journal of Machine Tools \& Manufacture.1995;35:701-16.

[6] Rentsch R, Pecat O, Brinksmeier E.Macro and micro process modeling of the cutting of carbon fiber reinforced plastics using FEM.Procedia Engineering.2011;10:1823-8.

[7] Ramesh MV, Seetharamu KN, Ganesan N, Sivakumar MS.Analysis of machining of FRPs using FEM.International Journal of Machine Tools \& Manufacture.1998;38:1531-49.

[8] Kalla D, Sheikh-Ahmad J, Twomey J.Prediction of cutting forces in helical end milling fiber reinforced polymers.International Journal of Machine Tools \& Manufacture.2010;50:882-91.

[9] Sheikh-Ahmad J, Twomey J, Kalla D, Lodhia P.MULTIPLE REGRESSION AND COMMITTEE NEURAL NETWORK FORCE PREDICTION MODELS IN MILLING FRP. Machining Science \& Technology.2007; volume 11:391-412.

[10] Wang DH, Ramulu M, Arola D.Orthogonal cutting mechanisms of graphite/epoxy composite. Part I: unidirectional laminate. International Journal of Machine Tools \& Manufacture.1995;35:1623-38.

[11] Zitoune R, Collombet F, Lachaud F, Piquet R, Pasquet P. Experiment - calculation comparison of the cutting conditions representative of the long fiber composite drilling phase. Composites 
Science \& technology.2005;65:455-66.

[12] Nayak D, Mahajan NBP.MACHINING STUDIES OF UD-FRP COMPOSITES PART 2: FINITE ELEMENT ANALYSIS. Machining Science \& Technology.2005;9:503-28.

[13] Rao GVG, Mahajan P, Bhatnagar N.Micro-mechanical modeling of machining of FRP composites - Cutting force analysis. Composites Science \& Technology.2007;67:579-93.

[14] Rao GVG, Mahajan P, Bhatnagar N.Machining of UD-GFRP composites chip formation mechanism.Composites Science \& Technology.2007;67:2271-81.

[15] Calzada KA, Kapoor SG, Devor RE, Samuel J, Srivastava AK.Modeling and interpretation of fiber orientation-based failure mechanisms in machining of carbon fiber-reinforced polymer composites.Journal of Manufacturing Processes.2012;14:141-9.

[16] Zhang LC, Zhang HJ, Wang XM.A force prediction model for cutting unidirectional fibre-reinforced plastics. Machining Science \& Technology An International Journal.2006;5(3):293-305.

[17] Zhang LC.Cutting composites: A discussion on mechanics modelling.Journal of Materials Processing Technology.2009;209:4548-52.

[18] $\mathrm{Xu} \mathrm{W,} \mathrm{Zhang} \mathrm{LC.On} \mathrm{the} \mathrm{mechanics} \mathrm{and} \mathrm{material} \mathrm{removal} \mathrm{mechanisms} \mathrm{of} \mathrm{vibration-assisted}$ cutting of unidirectional fibre-reinforced polymer composites. International Journal of Machine Tools \& Manufacture.2014:1-10.

[19] Jahromi AS, Bahr B.An analytical method for predicting cutting forces in orthogonal machining of unidirectional composites. Composites Science \& Technology.2010;70:2290-7.

[20] Qi Z, Zhang K, Cheng H, Wang D, Meng Q. Microscopic mechanism based force prediction in orthogonal cutting of unidirectional CFRP. International Journal of Advanced Manufacturing Technology.2015.

[21] Shaw M. Metal cutting principles. 3rd ed ed. Cambridge: MA:MIT Press,1954.

[22] Luttervelt CAV, Childs THC, Jawahir IS, Klocke F, Venuvinod PK, Altintas Y, et al.Present Situation and Future Trends in Modelling of Machining Operations Progress Report of the CIRP Working Group \&\#8216;Modelling of Machining Operations\&\#8217.CIRP Annals Manufacturing Technology.1998.

[23] Atkins AG.Modelling metal cutting using modern ductile fracture mechanics: quantitative explanations for some longstanding problems. International Journal of Mechanical Sciences.2003;45:373-96.

[24] Piggott MR.Theoretical estimation of fracture toughness of fibrous composites. Journal of Materials Science.1970;5:669-75.

[25] Ahmad J.Machining of Polymer Composites: Springer US,2009.

[26] Xiao Y, Matsubara T, Wang WX, Takao Y.Effect of Carbon Fiber Direction of Unidirectionally Reinforced Epoxy Composites on Frictional Behavior. Journal of the Society of Materials Science Japan.1998;47:618-24

[27] Everstine GC, Rogers TG.A Theory of Machining of Fiber-Reinforced Materials. Journal of Composite Materials.1971;5:94-106.

[28] Reifsnider KL, Case SW.Damage Tolerance and Durability of Material Systems. Damage Tolerance and Durability of Material Systems, by Kenneth L. Reifsnider, Scott W. Case, pp. 435. ISBN 0-471-15299-4. Wiley-VCH, April 2002.2002;-1:435.

[29] Huang P, Guo D, Wen S. Inerface Mechanics: Tsinghua University Press,2013.

[30] Hamilton GM, Goodman LE, Hamilton GM, Goodman LE.The Stress Field Created by a Circular 
Sliding Contact. Asme J.appl.mech.1966;33.

[31] Bryant MD, Keer LM.Rough Contact Between Elastically and Geometrically Identical Curved Bodies. Journal of Applied Mechanics.1982;49:345-52.

[32] Hetenyi M.Beams on Elastic Foundation: theory with applications in the fields of civil and mechanical engineering. University of Michigan.1971.

[33] Chen L, Zhang K, Cheng H, Qi Z, Meng Q. A cutting force predicting model in orthogonal machining of unidirectional CFRP for entire range of fiber orientation. International Journal of Advanced Manufacturing Technology, 2016; 1-14.

[34] An Q, Ming W, Cai X, Chen M. Study on the cutting mechanics characteristics of high-strength UD-CFRP laminates based on orthogonal cutting method. Composite Structures, 2015; 131:374-383.

[35] Agarwal H, Amaranath A, Jamthe Y, Gururaja S. An investigation of cutting mechanisms and strain fields during orthogonal cutting in CFRPs. Machining Science \& Technology, 2015; 416-439 